\title{
FICÇÕES DO EXCESSO \\ E DO SACRIFÍCIO: ROBERTO \\ BOLAÑO, MARCELO MIRISOLA \\ E WILLIAM BURROUGHS
}

Ângela Maria Dias

Recebido 14, abr. 2010 / Aprovado 14, mai. 2010

\section{Resumo:}

Este artigo pretende considerar a relação fundamental entre melancolia e trauma na dinâmica artística e literária de hoje e sublinhar o papel do sacrificio, como um ritual inscrito no processo de criação, desde a Modernidade. Estas molduras contemporâneas da invenção estética são engendradas, respectivamente pela alegoria e pela perspectiva da abjeção, aqui abordadas como modos correlatos de produção ficcional. O ensaio adota a visão de Bataille sobre o sacrifício para discutir os romances de três significativos autores: o chileno Roberto Bolaño, o brasileiro Marcelo Mirisola e o americano William Burroughs.

Palavras-chave: Trauma. Sacrifício. Alegoria. Abjeção 
A ausência de bússolas existenciais, característica da condição pós-moderna, em função do esclerosamento das grandes narrativas da modernidade, ${ }^{1}$ pode explicar os surtos de violência atual, na forma de protestos vazios de significações, como, por exemplo, os que ocorreram nos subúrbios parisienses, no outono de 2005. Mas, sobretudo, pode conduzir à apreensão de dois fenômenos cruciais e co-relacionados que, do meu ponto de vista, polarizam as manifestações artísticas e culturais da contemporaneidade: o luto(e/ou a melancolia) e o trauma.

A produção artística e literária marcada pelo luto adota o ponto de vista da melancolia, em relação à alteridade. Assim como o constata Benjamin, na estratégia alegórica, o olhar paralisado fita com indiferença a paisagem petrificada da História, ao considerar sua dinâmica como "fora dos eixos".

Um outro tipo de tendência ficcional desenvolve-se em torno do trauma, entendido por Lacan "como um encontro falhado com o real", na medida em que, conforme o enfatiza Hal Foster, "o real não pode ser representado, mas somente repetido e necessariamente repetido por compulsão" (Foster, p.132).

Comentando sobre a obra de Warhol, Foster firma que a repetição implicada no processo traumático é simultaneamente um esvaziamento de significação e uma defesa contra o afeto, por isso, além de não causar um efeito restaurador, o trauma manifesta uma obsessiva fixação num evento tratado então, como objeto de melancolia. Neste sentido, embora reconheça a especificidade de cada fenômeno, surpreendo uma insuspeita implicação entre trauma e melancolia.

Se a alegoria é a expressão privilegiada da melancolia, o trauma prefere um tipo de ficção marcada pela perspectiva da abjeção,como um tipo de escrita debruçada sobre a dissolvência de limites e identidades. Nesse sentido, o ponto de vista da indeterminação abjeta constitui a contrapartida à violência da técnica no corpo humano, destroçado na guerra e desterritorializado pelas próteses da velocidade e da comunicação, na cidade moderna. Entendida como modo produtivo e paradoxal, a abjeção conturba a sequência narrativa, desintegra a inteireza da obra e obsta a distância crítica, tanto na economia da composição, quanto na da recepção.

Baudelaire inaugura uma nova era na literatura quando integra, em sua poesia, a fascinação paradoxal pela vida urbana, além de inscrever, na própria obra, a violência processada pela técnica contra o corpo, e, a partir de então, conceber a escrita como um rito sacrificial. Daí em diante, a melancolia e o trauma, na condição de molduras ubíquas de construção formal, têm partilhado a lógica auto-sacrificial, tanto como ritual estético

1 Aqui aludo à conhecida interpretação de Lyotard em O Pós-Moderno (1986). auto-reflexivo, quanto como modo de produção.

No seu ensaio "A mutilação sacrificial na orelha cortada de Vincent Van Gogh", Bataille encara o sacrifício como: 
(...) a alteração radical da pessoa que pode ser indefinidamente associada a qualquer outra alteração sobrevinda na vida coletiva: por exemplo, a morte de uma pessoa próxima, a iniciação, a consumação da nova colheita... Uma ação como esta seria caracterizada pelo fato de ela ter a potência de libertar os elementos heterogêneos e romper a homogeneidade habitual da pessoa (...) O sacrifício considerado na sua fase essencial seria apenas um dejeto do que era apropriado a uma pessoa ou a um grupo (Bataille, 2004, p.70). ${ }^{2}$

Assim, o sacrifício, como um ritual que pressupõe a destruição da "habitual homogeneidade da pessoa" é relacionado tanto à abjeção, quanto à melancolia. A parcial identificação com o objeto perdido, operada pelo sujeito melancólico, resulta na dissociação do ego expressa pela melancolia, uma espécie de escrita em que as palavras são o duplo espectral do objeto incorporado pelo melancólico. Ao mesmo tempo, o ritual do sacrifício motiva as palavras a assumirem a perversão autodestrutiva e, contraditoriamente, a contorná-la, escapando do impulso à morte.

A abjeção, por seu turno, como um modo de produção paradoxal, está inter-relacionada com a desintegração da unidade ou de qualquer tipo de coerência. A esse respeito, Rosalind Krauss afirma que embora "Bataille tenha empregado o termo num grupo de textos não publicados e escritos na $2^{\mathrm{a}}$ metade dos anos 30, sob o título 'Abjection et les forms misérables', o uso do termo por Julia Kristeva é que tem influenciado a recente teorização do conceito, em relação à prática artística contemporânea" (Bois \& Krauss, 1997, p.236, 237).

Krauss desenvolve seu argumento explicando que Bataille concebe a noção em duas modalidades. Na primeira, ele identifica a abjeção social com uma força violenta e excludente operando dentro do estado moderno e a aproxima do lumpenproletariado, pelo que este segmento se esquiva à economia da representação social, tornando improvável a sua assimilação. Na segunda, ele considera o termo de um ponto de vista antropológico, no qual o sagrado, como uma força ambivalente, pode funcionar na vida social, tanto numa direção centrípeta e agregadora, quanto numa direção centrífuga, na medida em que significa, simultaneamente, o impuro ou o abjeto e o puro.

Em Formless: a User's Guide, Bois\&Krauss defendem que a perspectiva de Bataille sobre a abjeção é ligada ao informe (formless), termo que é concebido como um tipo de operação desclassificatória, que se propõe a rebaixar ou "dessublimar" noções, numa direção contrária aos imperativos do pensamento abstrato e à pura revelação do sentido, embutida na consagração da plenitude formal (Bois \& Krauss, 1997,p.25), característica do curso dominante da arte modernista. Nessa direção, o nú-

2 A tradução é de João Camillo Pena. cleo performativo do informe "não é nem um tema, nem uma 
substância, nem um conceito", e, por isto mesmo, participa do movimento geral do pensamento desenvolvido pelo filósofo, que ele elege chamar de "escatologia" ou "heterologia" (Bois \& Krauss, 1997, p.15).

Formless: a User's Guide é concebido como um catálogo de exposição realizada no Centro George Pompidou, em 1996, tendo sido, desde o início, um livro centrado numa proposição coerente, não apenas a respeito do passado da arte moderna (Arp, Duchamp, Picasso), mas também sobre sua recepção contemporânea e, possivelmente, sobre o seu futuro (Bois \& Krauss, p.15). Seu argumento central é baseado no verbete sobre o informe, que Bataille escreveu para a revista Documents, publicada entre 1927 e 1930, e voltada para o relacionamento entre certas práticas artísticas e fenômenos etnográficos.

INFORME - Um dicionário começa quando ele não mais dá o significado das palavras, mas as suas tarefas. Assim, o informe não é apenas um adjetivo tendo um dado significado, mas um termo que serve para rebaixar as coisas no mundo, que geralmente requer que cada coisa tenha a sua forma. $\mathrm{O}$ que ele designa não tem direitos em qualquer sentido e se encontra disforme em todo lugar, como uma aranha ou uma minhoca. Na realidade, para que as mentes acadêmicas sejam felizes, o universo deve tomar forma. Toda filosofia não tem outro objetivo: é uma maneira de vestir tudo o que é. Por outro lado, afirmar que o universo não se parece a nada, e é apenas quantidades disformes, é como dizer que o universo é algo como uma aranha ou uma cusparada (Bataille, 2004, p.31). ${ }^{3}$

Ao pensar a heterologia, como a "ciência do totalmente outro", Bataille, influenciado por Freud, é levado a observar o duplo uso de muitas palavras (como, por exemplo, pharmacon) que, por sua vez, reflete a dupla função de determinados órgãos (a boca e a genitália, por exemplo), habitualmente reprimida pelo processo civilizatório. Nesta linha, as palavras e os corpos refletiriam a divisão de tudo o que existe, em duas partes inassimiláveis e paradoxais: uma alta e outra baixa, uma bem formada e a outra informe, uma homogênea e a outra heterogênea (Bois \& Krauss, 1997,p.52). A esse respeito, Bois \& Krauss comentam que a primeira vez na qual o filósofo francês usa o termo "heterogeneidade" ("A mutilação sacrificial e a orelha cortada de Vincent Van Gogh"), quer vinculá-lo à noção de sacrifício entendido como "o poder de liberar elementos heterogêneos e de quebrar a habitual homogeneidade do individual"(Bataille, p.70).

Assim, a heterologia, entendida como "o completo reverso do processo filosófico" (Bataille, p.97) vai buscar sempre o outro lado, a margem reprimida e rebaixada de tudo o que é elevado ou ideal, em nome da concretude da matéria elementar, irredutível

3 A tradução é de minha autoria, bem como todas as seguintes. a qualquer conceito.

Esta "desformalização" promovida por Bataille, em nome da matéria - o resto não mais reciclável pelos imperativos do 
pensamento abstrato - será tomada por Bois \& Krauss para interpretar a posição do filósofo diante da arte moderna, formulada durante a estratégia de Documents. Com este objetivo, os críticos organizaram as obras na exposição, segundo "quatro diferentes vetores", capazes de manifestarem-se contra a formalização modernista, em consonância com o pensamento de Bataille: a horizontalidade, o baixo materialismo, a pulsação e a entropia.

A primeira modalidade destina-se a desfazer a verticalidade do campo visual, implicada tanto na sublimação que separa o observador de seu corpo, quanto na relação hierárquica entre homens e animais. A segunda tenta caracterizar a crítica que Bataille dirige aos materialismos, em função das relações hierárquicas que estabelecem. Contra tal procedimento, o filósofo busca centrar-se num tipo de matéria que não possa ser reabsorvida pela imagem, ou que não possa prestar-se a nenhum tipo de deslocamento metafórico. A terceira modalidade, embora não tenha feito parte do vocabulário do filósofo, é invocada pelos críticos, na medida em que ataca a exclusão do tempo no campo visual, característica do modernismo. E, nesse sentido, a pulsação ativaria o processo de infinita permutação que Bataille adota em sua narrativa A história do olho (1928), "ao anular a metáfora, através de um excesso metafórico" (Bois \& Krauss, p.32). Por fim, a entropia que, entendida como degradação de energia rumo à indiferenciação, consiste também num modo compatível com o rebaixamento que o filósofo visa impor às palavras, na direção do informe.

Por conseguinte, tanto o informe, entendido como uma operação desformalizadora, quanto o sacrifício, concebido como um modo de produção, encarnariam uma tendência que, subjacente na Modernidade, emerge, com mais clareza, durante a Pós-Modernidade.

Nesse sentido, a perspectiva de Bataille sobre a "ruptura da homogeneidade pessoal" como condição para a "maravilhosa liberdade do sacrifício" vai resultar na vinculação entre esta última experiência e os processos de expiação, os períodos de luto e a orgia, como prática (Bataille, p.68, 70). Os três romances que passo, em seguida, a comentar dramatizam tais sintomas.

O primeiro é o Noturno do Chile, de Roberto Bolaño, que apresenta uma excelente recriação da cerimônia do luto. Ambientado no Chile dos anos 70, é uma confissão transtornada envolvendo a Opus Dei, Pinochet e sórdidas conexões entre a Igreja e o Estado. O estilo do narrador encena um esforço desesperado para evitar, na eminência da morte, reminiscências e memórias inoportunas e ou intempestivas. Com efeito, Padre Urrutia, entre melancolia, raiva e culpa, tenta, como pode, escapar do lutuoso reconhecimento de sua corrupção moral e da conivência política que sempre manteve com a brutalidade da ditadura chilena. Entretanto, apesar de todo esforço, ele 
não consegue. Por isso mesmo, o seu solilóquio termina com a alusão ao dejeto indizível: "E depois se desencadeia a tormenta de merda" (Bolaño, 2000, p.84).

O romance desconstrói importantes conquistas da literatura romântica. $\mathrm{O}$ nacionalismo é virado de ponta-cabeça e o Chile é apresentado como um país traído, pervertido pelo autoritarismo e pela corrupção social. A música melancólica do título, o "noturno", por sua qualidade de composição meditativa, indicia a possibilidade de que o narrador desenvolva suas memórias num tom auto-celebratório. Mas a face do "jovem envelhecido" (Bolaño, 2000, p.6), funcionando como o alter-ego de Urrutia, frustra a sua paz e seqüestra a aura de respeitabilidade buscada pelo padre agonizante.

Finalmente, a autobiografia que, como um gênero romântico típico, é perfeitamente compatível com o ritmo musical das reminiscências, também é rebaixada e desacreditada, na medida em que a dicção do protagonista, apostando na dignidade e na profundidade emocional do tom a ser adotado, imprime ao início do solilóquio uma solenidade, aos poucos perdida:

É preciso esclarecer alguns pontos. Por isso, vou me apoiar no cotovelo e levantar a cabeça, minha nobre e trêmula cabeça, e buscarei no cantinho das reminiscências aqueles atos que me justificam e, portanto, desdizem as infâmias que o jovem envelhecido espalhou para meu descrédito numa só noite relampejante. Meu suposto descrédito (Bolaño, 2000, p.6).

A configuração alegórica da narrativa cria um vínculo entre o sistema literário e os destinos nacionais através de muitas alusões eruditas e estórias honoráveis. A referência ao trovador Sordello - um lombardo, do século XIII, nascido em Mântua - funciona neste sentido. Ele é, talvez, mais lembrado por ter sido citado por outros poetas - Dante Alighieri, em De vulgari eloquentia e no Purgatorio d'A Divina Comédia e Pound nos Cantos - e tem-se mantido na tradição como um símbolo de devoção patriótica.

Ao combinar a pomposa promessa de imortalidade com "desolação e esquecimento", a ambígua estória sobre a Colina dos Heróis expõe a fragilidade do discurso auto-consagrador do Padre Urrutia. Assim, a sua perplexidade diante do amigo Farewell faz emergir o poder desconstrutor da narrativa e a corrosão subliminar que promove contra a alienação defensiva dos personagens:

Depois Farewell repetiu: entende? entende?, enquanto pedíamos café e as pessoas na rua, apressavam-se premidas por uma ânsia incompreensível de chegar em casa, e suas sombras se projetavam uma atrás da outra, cada vez mais rápido, nas paredes do restaurante onde Farewell e eu mantínhamos con- 
tra ventos e marés, (...) uma imobilidade apenas interrompida pelos gestos das nossas mãos, que aproximavam as xícaras de café dos lábios, (...) a imobilidade de Farewell, só quebrada então por um ligeiro movimento ocular, foi adquirindo para mim conotações de terror infinito ou de terror disparado para o infinito, que é, aliás, o destino do terror, elevar-se, elevar-se e não terminar nunca, daí nossa aflição (Bolaño, 2000, p.35).

Conforme observa Gonzalo Aguiar, a imaginação ficcional de Bolaño produz uma galeria de personagens que participam tanto da criação literária, quanto do terror militarista e, nesse sentido, o criticismo de seus romances poderia ilustrar a frase emblemática de Benjamin, segundo a qual " nunca houve um monumento da cultura que não fosse também um monumento da barbárie"(Benjamin, 1985, p.225). Noturno do Chile termina com o fluxo de memórias de Urrutia transformado em "tormenta de merda" (Bolaño, 2000, p.86). Nada mais apropriado para manifestar o informe como a diferença embutida na aura das belas formas.

Animais em Extinção de Marcelo Mirisola, por sua vez, dramatiza a orgia, numa narrativa em que o narrador em primeira pessoa desempenha o papel do algoz. O enredo desenvolve-se pela fala loquaz de um narrador delirante que elege uma prostituta-criança como testemunha de sua própria rememoração. O tom da narrativa é bizarro, uma combinação de ironia ácida com cínico criticismo diante da sociedade e da vida literária brasileiras, numa espécie de sátira desabrida a toda espécie de convencionalismo.

A linguagem, repleta de gíria e pornografia, e a distância entre autor e narrador, de tal forma dissolvida, podem levar a crer um leitor menos atento que a obra não passa de uma brincadeira ou de uma piada excessiva. Mirisola é, sem dúvida, um autor provocativo de obra controversa, capaz de suscitar reações bem díspares. Vanusa, a prostituta-criança, que é chamada pelo narrador de "Sherazade às avessas", é sacrificada e o narrador tenta ocupar o seu lugar, confirmando o que Bataille afirma sobre o processo: "Aquele que sacrifica é livre - livre para abandonar-se ao mesmo fluxo, livre para continuamente identificar-se com a vítima, e vomitar seu próprio ser como vomitou um pedaço de si mesmo ou um absurdo" (Bataille, p. 70).

O cinismo do estilo alude à bipolaridade entre as posturas "cynical" e "kynical",tais como concebidas por Peter Sloterdijk. De acordo com o filósofo alemão, a posição cínica, de um lado, consiste "nas operações da razão iluminista na história (...) concebidas como o eterno retorno do mesmo" e, de outro, produz "o cinismo do poder e suas instituições". Por sua vez, a "revolta kynical" constitui o antídoto da falsa consciência do homem iluminista, na medida em que encarna a tradição do "anarquismo somático" de Diógenes, o grego kynical (Sloter- 
dijk, XVI).Certamente a inteligência corrosiva da linguagem de Mirisola põe em prática a herança do grego filósofo: sua "vibrante gargalhada satírica" e sua postura desafiadora contra a corrupção da esfera pública.

A afetação e o narcisismo dos heróis da mídia constituem, segundo Mirisola, uma espécie de "jardim de infância", onde todos os assuntos são banalizados e discutidos numa maneira superficial e infantilizada. Seu trabalho constitui uma crônica ácida, na qual os comportamentos sociais e as mentalidades são criticadas a partir de uma perspectiva bem subjetiva e peculiar.

A combinação de gêneros - lirismo, narrativa, diário, crônica - concebe uma espécie de auto-ficção, na qual o tom expressionista manifesta "a experiência da subjetividade como uma dinâmica fundamentalmente imprevisível" (Murphy, p.18). Por isso mesmo, o ponto de vista idiossincrático do narrador constitui o centro do enredo e sua verdadeira motivação, o que ocasiona a disposição errática e fragmentária da trama, não necessariamente vinculada a um conflito específico.

A "poética iconoclasta" (Murphy, p.39) deste romance o opera segundo um programa de "desestetização" da memória narrativa. Nesse sentido, Scherazade não encarna a heroína imemorial que é responsável pela nobre tarefa de renovar a vida através da capacidade de desdobrar narrativas. Ao invés disso, ela é então subvertida e desclassificada, ao transformar-se em Vanusa, uma prostituta criança e analfabeta, que é testemunha do desespero e da desolação do narrador.

Assim, as lembranças e reminiscências do narrador são transformadas em Animais em Extinção e a positividade da atitude memorialista é testemunhada por uma criança sacrificada e cativa, completamente incapaz de entender o que ouve. Esta versão rebaixada do narrador tradicional benjaminiano anula a sabedoria de quem fala - colocando o narrador na pervertida posição de quem se aproveita e maltrata uma criança prostituída, e, de sobra - sequestra a propalada transmissibilidade da experiência, já que não há comunidade e nem comunicabilidade. O que resta, o refugo, o intratável sobejo é então o romance de Mirisola, escritura da solidão de um narrador corrupto, no limite com a pornografia.

De acordo com Richard Murphy, este projeto de "dessublimação" é desenvolvido pelas tendências vanguardistas não idealistas e constitui "uma subversão cínica da arte, misturando-a ao nível mais banal da vida, por meio destruição do mais remoto sentido de harmonia estética e estruturação orgânica" (Murphy, p.34). Nesta linha de reflexão, eu sugeriria que Mirisola pode ser visto como um legítimo herdeiro da dessublimização expressionista, ao mesmo tempo como um legítimo operador do informe batailliano. 
Finalmente, Almoço Nu (Naked Lunch) de William Burroughs - um livro que é visto pelo próprio autor como um não romance - pode ser considerado com um exercício metamórfico ou um ato de expiação. Escrito durante nove longos anos de dependência química de drogas e alguns períodos de abstinência, este livro nunca seguiu um plano prévio e foi concluído em virtude da premência do editor, a Olympia Press, em publicá-lo, durante 1959.

Almoço $\mathrm{Nu}$, desde o seu título insólito, transforma uma experiência cruel e degradante em literatura vigorosa. Como observa, a respeito, Norman Mailer:

Mas o que é fascinante para mim é que há uma estrutura
no livro (...) que é, sem dúvida, imperfeita. Eu acho que uma
das razões pelas quais não podemos considerá-lo um grande
livro, como Em Busca do Tempo Perdido ou, ainda, Ulisses,
é a imperfeição da sua estrutura. Não há dúvidas quanto ao
talento do autor, ainda que excitado e inflamado pelo vício, que
também o fere. Assim, há um sentimento de grande tortura
na composição do livro. O que me impressiona é que, através
de todas as privações e sofrimentos da dependência, ele ainda
mantém um estilo e um esquema no livro, com um sentido pro-
fundo. É curioso como todos os seus temas se auto-remetem.
Eu não sei como o livro foi composto. Os ingredientes são tão
excepcionais que é como se você tivesse um banquete de trin-
ta, quarenta componentes. Você pode comê-los em qualquer
ordem, pode misturá-los. Os temas são tão entrelaçados que
qualquer página, ao lado de qualquer outra, é capaz de criar
uma aura. Pode ser que este livro não tenha outra estrutura
que a profundidade da experiência que o autor viveu, ou pode
ser, ainda, que haja nele uma firmeza subjacente (Mailer. In:
Burroughs, p. XIV, XV).

A complexidade e a diversidade das técnicas dispostas nesta miscelânea narrativa desenvolvem uma "teoria da dependência de drogas (...) aplicada como modelo para muitos outros vícios: o vício de sexo, o vício de bens materiais, o vício de poder" (Ginsberg. In: Burroughs, xix). A veia satírica do narrador constitui uma espécie de estilo de escritor religioso comprometido com a imaginação de situações nas quais a humanidade aparece como destituída de alma. Não é por outra razão que Mailer enfatiza no relato a imaginação do Inferno, "como culminação e produto final da revolução científica" (Mailer. In: Burroughs, xviii).

Esta 'gradação fantástica de ritmos velozes' disposta num método-mosaico (Ginsberg. In: Burroughs, xxxii, xxxiii) manifesta uma espécie de compulsão surrealista. A imaginação futurista dispõe a espiral consumista da produção de necessidades e o incremento da desumanização como as duas faces da mesma moeda.

A narrativa de Burroughs, ao propiciar a confluência entre literatura e experiência de limites, configura, assim como os 
demais relatos referidos, a correlação entre o sacrifício, como modo de produção do heterogêneo, e o informe, como operação de rebaixamento e emergência do disforme, no âmago da forma.

A inscrição do sacrifício nos textos comentados, ao manifestar a diferença, como sintoma, no corpo da escrita em primeira pessoa das três obras, pode apontar para as suas diversas faturas memorialísticas.

A primeira, de Roberto Bolaño, perfaz o movimento da ficcionalização da memória, ao apresentar o personagem, Padre Urrutia, em seu doloroso processo de auto-reconhecimento. A segunda, de Marcelo Mirisola, em seu exibicionismo farsesco e dilacerado, consuma a escandalosa autoficção de um autor que não se farta de revelar-se, deslocar-se, deformar-se, a cada livro, em que a confusão entre autor, narrador e personagem os faz deslizarem um pelo outro e confundirem-se, entre sarcasmo e derrisão. A terceira, de William Burroughs, constitui uma espécie de marco precursor da autoficção, na medida em que traduz a tenebrosa experiência do vício em drogas num pesadelo narrativo tormentoso e fragmentário, em que reminiscências pessoais se misturam e se intercalam com ficções mórbidas sobre sadismo e controle social.

É como se, o movimento beat, no alvorecer dos anos 60, aqui referido por um de seus ícones, tivesse desmentido antecipadamente a morte do autor, mais adiante decretada pelos franceses. $\mathrm{O}$ seu ardor neo-romântico, pela vinculação entre arte e vida que dramatiza, inegavelmente cruza-se ao compromisso com a contemporaneidade, bem nítido pela incorporação literária da fala oral, radicalmente anti-academicista. Nesse sentido, esses atores-escritores podem ser vistos como os precursores da pós-vanguarda, no que souberam atualizar a vertente crítica e dessublimizante das vanguardas modernas, em relação à arte formalista e abstrata da alta modernidade.

\begin{abstract}
:
This paper aims to consider the fundamental relationship between melancholy and trauma in today's artistic and literary life, and to stress the role of sacrifice as a ritual which has been inscribed in the creation process since Modernity. These contemporary frames for aesthetic invention may be processed respectively by allegory and the perception of abjection as correlated modes of fictional production. The paper draws on Bataille's view of sacrifice to discuss the novels of three significant writers: the Chilean Roberto Bolaño, the Brazilian Marcelo Mirisola, and the American William Burroughs.
\end{abstract}


Keywords: Melancholy, Trauma, Sacrifice, Allegory, Abjection

\section{Referências}

BATAILLE, Georges. Visions of Excess: Selected Writings, 1927-1939. Minneapolis, University of Minnesota Press, 2004.

BOIS, Yve-Alain \& KRAUSS, Rosalind . Formless A User's Guide. New York, Zone Books, 1997.

BOLAÑO, Roberto. By Night in Chile. Trans. Chris Andrews. New York, New Directions Books, 2003.

BURROUGHS, William, S. Naked Lunch. New York, Grove Weidenfeld, 1959.

DE GRAZIA, Edward \& MAILER, Norman \& GINSBERG, Allen. "Excerpts from The Boston Trial of Naked Lunch". In: BURROUGHS, William, S. Naked Lunch. New York, Grove Weidenfeld, 1959, p.X-XXXVI.

FOSTER, Hal. The Return of the Real: the Avant-garde at the End of the Century. Cambridge/Massachussetts, MIT Press, 1996.

KRISTEVA, Julia. Powers of Horror. An Essay on Abjection. Trans. Leon S. Roudiez. New York, Columbia University Press, 1982.

- - - Sentido e Contra-senso da Revolta Poderes e Limites da Psicanálise I. Trad. Ana Maria Scherer. Rio de Janeiro, Rocco, 2000. MIRISOLA, Marcelo. Animais em Extinção. Rio de Janeiro, Record, 2008.

MURPHY, Richard. Theorizing the Avant-Garde Modernism, Expressionism and the Problem of Postmodernity. Cambridge/New York, Cambridge University Press, 1999.

RICHARDSON, Michael. “Introduction”. In: BATAILLE, Georges. The Absence of Myth Writings on Surrealism. Edited,translated and introduced by Michael Richardson. London/New York, Verso, 2006.

SLOTERDIJK, Peter. Critique of Cynical Reason. Foreword by Andréas Huyssen. Translation by Michael Eldred. Minneapolis/ London, University of Minnesota Press, 1997. 